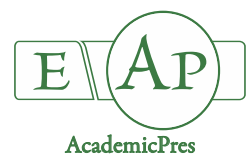

\title{
Study on Leaf Epidermis Structure and Dust-Retention Ability of Five Machilus Species
}

\author{
Xinru HE ${ }^{1}$, Yumu ZHANG ${ }^{2}$, Bing $S \mathrm{ZN}^{1}$, Pujie $\mathrm{WEI}^{1}$, Die $\mathrm{HU}^{1 *}$ \\ ${ }^{1}$ Germplasm Resources Evaluation and Innovation Center of Phoebe Yangtze University, Jingzhou 434025, Hubei, China; \\ hexinru10@163.com;690593440@qq.com;1902113155@qq.com;1293446583@qq.com (*corresponding author) \\ 2Shaoguan Agricultural Bureau, Guangdong, China; zhangyumu05@163.com
}

\begin{abstract}
Taking the leaves of five Machilus species as a research object, they are Machilus oreophila, Machilus chinensis, Machilus microcarpa, Machilus lichuanensis and Machilus suaveolens. By measuring leaf surface area, cell length and width, the total dust retention, $\mathrm{pH}$ value of retention fluid and the content of $\mathrm{Pb}, \mathrm{Cr}, \mathrm{Fe}, \mathrm{Cu}$ and $\mathrm{Cd}$ of metallic elements were measured, and compare the dust retention of five plant seedling leaves ability. The results showed that: the leaves of different kinds of Machilus have different dust abilities. Comprehensive analysis can be obtained from five kinds of Machilus dust ability in descending order of $M$. suaveolens $>$ M. lichuanensis $>$ M. chinensis $>$ M. microcarpa $>$ M. oreophila.
\end{abstract}

Keywords: dust-retention; epidermal cell; leaf morphology; Machilus; metal element

\section{Introduction}

There are about 100 species of Machilus in Lauraceae family in the world and more than 70 species in China, mainly distributed in southwest, south central to Taiwan, north to Shandong, Hubei and southwest Shanxi (Wu and Raven, 2000). Most of the Machilus plants were trees or shrubs, which were the most important economic forests in southern China, most of which were characterized by tropical and subtropical forests. The species has a high utilization value. The whole plant can extract aromatic oil, the seed oil can be used as a lubricant, the leaves and bark can be used as a purifying agent for dyes and drinking water, and a blending agent for various incense (Guo et al., 2017). And it has a strong ecological function, can effectively conserve water and soil, water conservation; plant leaves can absorb harmful substances in the air, purify the air, so as to achieve the effect of dust control and dust retention.

As early as last century, The dust retention effect of birch forest near open pit mine was studied by Spitsyna et al. (1991), the dust-retaining effect of urban forest land was studied by Beckett et al. (1998), and the dust-retaining ability of the Mexican road greening plant Oleander was studied by Dongarra et al. (2003), which proved that individual plants of all life types in nature have dust retention. Scholars began to study the dust retention ability of plants. High-end technologies such as micro-analysis (Bogo et al., 2003) have been successfully applied to the analysis of various elements in dust adsorbed by leaves, and have begun to study the toxicity of these fine particles. The combination of micro-analysis and surface analysis has made the analysis depth often less than 1 micron. Tomasevic (2005) showed that there was a great correlation between the composition of foliar dust and the contaminated elements in leaves. At present, the research on plant dust suppression has become a hot spot in China, and its ecological application potential is enormous. It is not only suitable for street trees and shade trees, but also has good wind and sand-fixing ability. It can be widely used in urban greening.

In this study, the dust-retaining ability of the Machilus plants and its influencing factors were compared, and the dust-retaining ability of the same species was compared. It can be intuitively found that the adsorption capacity of various heavy metal elements was strong and weak, and the best use of the materials, to maximize its ecological benefits, to tap the greater ecological potential of the Machilus plants. In the future practical application, it can be used as a reference to explore the feasibility of Machilus plants in garden application, provide scientific guidance for the selection of plants, and obtain the optimal plant application program to give full play to the ecological benefits of plants. Improve air quality and create a comfortable and healthy living environment. 


\section{Materials and Methods}

\section{Plant materials and treatments}

The experimental materials were leaves of $M$. oreophila, $M$. chinensis, $M$. microcarpa, $M$. lichuanensis and $M$. suaveolens. The mother plants were all three years old.

In April 2018, the leaves of five Machilus species plants were collected in the bonsai Garden of Yangtze University. Choose healthy genus of genus, each plant in the same growing environment; select the same position of the same part of the leaves when collecting samples. Each plant was randomly selected from 180 leaves. After being taken down, it was sealed in a sealed bag and taken back to the laboratory for treatment. Each plant leaf was divided into three groups of 60 pieces each, and three replicates were set in the experiment.

\section{Determination of various indicators of leaves}

Leaf morphology observation: five leaf samples of the seedlings of Machilus were placed in a DFC550 stereo microscope to observe the leaf shape, tip, veins and surface attachments of the leaves. The epidermis cells of the leaves of five Machilus species were observed by light microscopy, and their dimensions were measured by microscopic micrometer.

Leaf area determination: each of the leaves of the Machilus was 30 pieces, and the leaves were scanned with a scanner (resolution $300 \mathrm{dpi}$ ), and then the length, width and area of the leaves were measured by computer software. Calculated as follows:

Actual blade length $(\mathrm{cm})=$ measured length pixel points $\times(2.54$ / scanner resolution $)$

Actual blade width $(\mathrm{cm})=$ measured width pixel number $\times(2.54 /$ scanner resolution $)$

Actual blade area $\left(\mathrm{cm}^{2}\right)=(2.54 /$ scanner resolution $) 2$ $\times$ measured number of pixels

Determination of total dust retention, $\mathrm{pH}$ value of heavy dust and heavy metal elements: (1) the collected leaves of five kinds of Machilus were weighed and recorded separately. After the leaves were washed and dried, they were weighed again. The difference between the two weighing weights was the total dust retention of the leaves. (2) Five sets of leaf samples were placed in five large beakers, each of which was poured into $200 \mathrm{~mL}$ of distilled water. After soaking the leaves for $2 \mathrm{~h}$, the leaves were pinched out with tweezers, and the remaining dipping solution was the dustretaining test solution. First adjust the pHS-3e type acidity meter with $\mathrm{pH} 6.86$ and $\mathrm{pH} 9.18$ standard solution. The two values were repeated until the value was stable and will not be changed arbitrarily. Then the composite glass electrode was inserted into the test solution to determine its $\mathrm{pH}$. (3) The contents of heavy metal elements $\mathrm{Fe}, \mathrm{Cu}, \mathrm{Pb}$, $\mathrm{Cr}$ and $\mathrm{Cd}$ in the dust-removing liquids of five Machilus species were determined by atomic absorption spectrophotometry (Abdel-Halim, 2003).

\section{Statistical analysis}

Data were presented as mean value of each treatment. The results represent the means \pm standard error with each experiment performed in triplicate. Data were analyzed using SPSS 24.0 for Windows and differences in the treatment means were compared with Duncan's multiple range test at the $P \leq 0.05$ level.

\section{Results}

\section{Leaf morphology observation}

The leaves of five Machilus species plants were observed by stereo microscope, and were compared from leaf shape, tip, vein and surface attachment. The leaf shape was mainly lanceolate and elliptical, the leaf tip was acuminate, the leaf texture was leathery, and the veins were different. The surface of $M$. chinensis and $M$. microcarpa, was hairless, while the other three surfaces were hairy (Table 1).

\section{Comparison of leaf area and size}

The leaf area and size of five Machilus species were measured and calculated (Fig. 1). The leaf area of five Machilus species was found: M. lichuanensis was the largest, with an average of $14.77 \mathrm{~cm}^{2}$, and $M$. suaveolens was the smallest, with an average of $10.698 \mathrm{~cm}^{2}$. There was no significant difference in the leaf area between $M$. oreophila, $M$. microcarpa and $M$. lichuanensis, which was significantly different from that of $M$. chinensis. There was a significant difference between the leaf area and the leaf area of $M$. suaveolens. The leaf length of five Machilus species: the longest of $M$. oreophila, the average was $12.486 \mathrm{~cm}$, the shortest of $M$. chinensis, the average was $7.49 \mathrm{~cm}$, and the leaf length of $M$. oreophila was significantly different from that of $M$. chinensis, $M$. microcarpa, $M$. lichuanensis and $M$. suaveolens. The leaf width of five Machilus species: the widest of $M$. lichuanensis, the average was $2.556 \mathrm{~cm}$, the narrowest of $M$. suaveolens, the average is $1.461 \mathrm{~cm}$, and there were significant differences in leaf widths between $M$. suaveolens and $M$. chinensis, $M$. microcarpa, M. oreophila and M. lichuanensis.

\section{Observation and comparison of leaf epidermal cells}

The epidermal cells on the leaves of five Machilus species were observed by electron microscopy. Thirty cells in the field of view were randomly selected, and the length and width of the epidermis cells were measured (Fig. 2). The upper epithelial cells of $M$. lichuanensis were the longest and the widest, and there were significant differences in the length of upper epidermal cells among $M$. chinensis, $M$. suaveolens, $M$. oreophila and $M$. microcarpa; There was no significant difference in the width of upper epithelial cells between $M$. microcarpa and $M$. lichuanensis, but there was significant difference in the width of upper epithelial cells among $M$. oreophila, $M$. chinensis and $M$. suaveolens. The lower epidermal cells of $M$. microcarpa were the longest. There were significant differences in the length and width of the lower epidermal cells of $M$. oreophila, $M$. chinensis, $M$. lichuanensis and M. suaveolens. 
1226

Comparison of total dust retention and $p H$ value of dustretaining liquid

The total dust retention and the $\mathrm{pH}$ value of the dustretaining liquids of five Machilus species were determined (Fig. 3). The total dust retention of $M$. suaveolens was the largest, with an average of $120 \mathrm{mg}$. M. oreophila was the smallest with an average of $77 \mathrm{mg}$. Under similar growth conditions, there were significant differences in the total dust retention of the five species of the Machilus. The $\mathrm{pH}$ values of the five species of Machilus were neutral. $M$. microcarpa was the highest with an average of 7.85. The lowest was $M$. oreophila and the average was 7.57 .

Comparison of heavy metal elements in leaf dust per unit area

The heavy metal elements $\mathrm{Pb}, \mathrm{Cr}, \mathrm{Fe}, \mathrm{Cu}$, and $\mathrm{Cd}$ in the leaf dust area of the five species of the Machilus were compared (Fig. 4).

$\mathrm{Pb}$ content: the highest value of $M$. suaveolens was 0.13 $\mathrm{mg} / \mathrm{cm}^{2}$, the lowest of $M$. oreophila was $0.06 \mathrm{mg} / \mathrm{cm}^{2}$. There was a significant difference in the content of heavy metal $\mathrm{Pb}$ in the leaf area of $M$. suaveolens, $M$. oreophila, $M$. chinensis, $M$. microcarpa and $M$. lichuanensis. However, the difference in $\mathrm{Pb}$ content per unit leaf area among $M$. chinensis, $M$. microcarpa and $M$. lichuanensis was not significant.

$\mathrm{Cr}$ content: The highest content of $M$. suaveolens, the average was $0.047 \mathrm{mg} / \mathrm{cm}^{2}$, the lowest in $M$. oreophila, the average was $0.009 \mathrm{mg} / \mathrm{cm}^{2}$. Under the similar growth environment, there was a significant difference in the content of heavy metal $\mathrm{Cr}$ in the leaf area among $M$. suaveolens, $M$. oreophila, $M$. chinensis, $M$. microcarpa and $M$. lichuanensis.

Fe content: the highest in $M$. lichuanensis was 0.128 $\mathrm{mg} / \mathrm{cm}^{2}$, the lowest in $M$. microcarpa was $0.067 \mathrm{mg} / \mathrm{cm}^{2}$. There was no significant difference in the content of $\mathrm{Fe}$ in the leaf area of $M$. chinensis and $M$. lichuanensis, $M$. oreophila and $M$. suaveolens. But there was a significant difference in the leaf area per unit area among $M$. chinensis, $M$. lichuanensis, $M$. oreophila, $M$. microcarpa and $M$. suaveolens.

$\mathrm{Cu}$ content: The highest content of $M$. suaveolens was $0.023 \mathrm{mg} / \mathrm{cm}^{2}$, the lowest was $M$. oreophila, the average was $0.012 \mathrm{mg} / \mathrm{cm}^{2}$. There was no significant difference in the content of heavy metal $\mathrm{Cu}$ in the leaf area of $M$. chinensis and $M$. lichuanensis. There were significant differences in $\mathrm{Cu}$ content per unit leaf area among $M$. suaveolens, $M$. oreophila, $M$. microcarpa, $M$. chinensis and $M$. lichuanensis

Cd content: $M$. suaveolens was the highest with an average of $0.015 \mathrm{mg} / \mathrm{cm}^{2}$, and $M$. oreophila was the lowest with an average of $0.011 \mathrm{mg} / \mathrm{cm}^{2}$. There was no significant difference in the $\mathrm{Cd}$ content of the heavy metal elements in the leaf area of $M$. oreophila and $M$. lichuanensis, $M$. chinensis and $M$. suaveolens. But there was a significant difference in the $\mathrm{Cd}$ content per unit area among $M$. chinensis, $M$. suaveolens, $M$. microcarpa, $M$. oreophila and $M$. lichuanensis.

Table 1. Comparison of leaf morphology of five Machilus species

\begin{tabular}{|c|c|c|c|c|c|}
\hline Species name & Leaf shape & Leaf apex & Leaf texture & Epidermal appendages & Leaf vein \\
\hline M. oreophila & long lanceolate & apex acuminate & thin leathery & a little pubescent & fine honeycomb shape \\
\hline M. chinensis & long ellipse or lanceolate & $\begin{array}{l}\text { a blunt or short } \\
\text { acuminate apex }\end{array}$ & leathery & glabrous & $\begin{array}{c}\text { honeycomb shallow fossa } \\
\text { points }\end{array}$ \\
\hline M. microcarpa & $\begin{array}{c}\text { oval or rectangular round } \\
\text { lanceolate }\end{array}$ & apex caudate acuminate & leathery & glabrous & $\begin{array}{l}\text { the veins are densely } \\
\text { reticulated on both sides }\end{array}$ \\
\hline M. lichuanensis & oval or narrow oval & $\begin{array}{l}\text { apex short acuminate to } \\
\text { acute }\end{array}$ & leathery & dense villi & $\begin{array}{c}\text { the reticular vein is visible on } \\
\text { the ventral side }\end{array}$ \\
\hline M. suaveolens & $\begin{array}{c}\text { oval or elliptical inverted } \\
\text { lanceolate }\end{array}$ & a blunt sharp point & leathery & dense villi & honeycomb-like pits \\
\hline
\end{tabular}
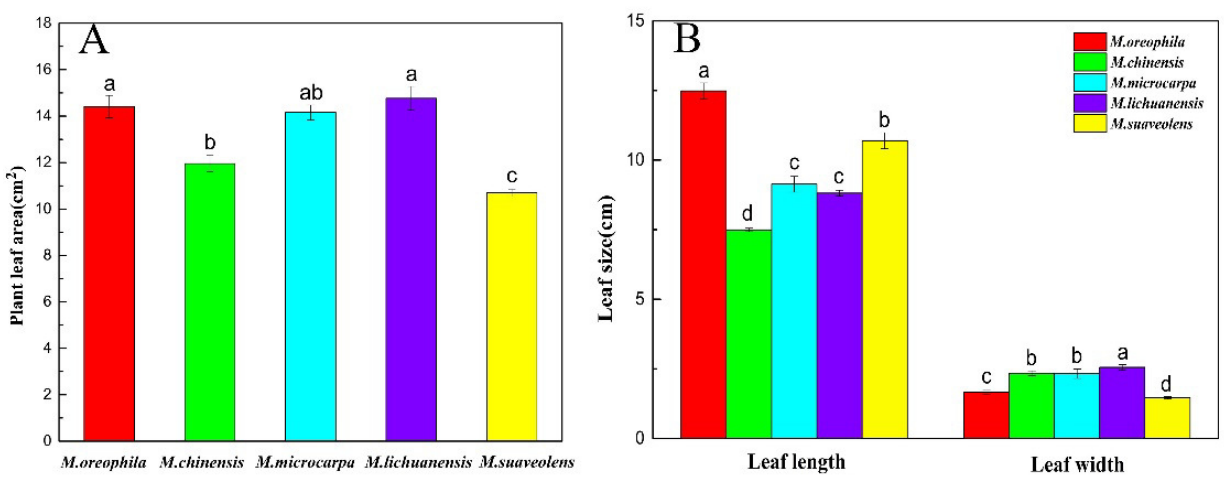

Fig. 1. Comparison of the leaf area and leaf size of 5 species of Machilus. A and B represent leaf area, leaf length and width, respectively. Each value represents the mean of three replicates of each plant, and the different normal letters in the same columns indicate significant differences at $\mathrm{P}<0.05$ 

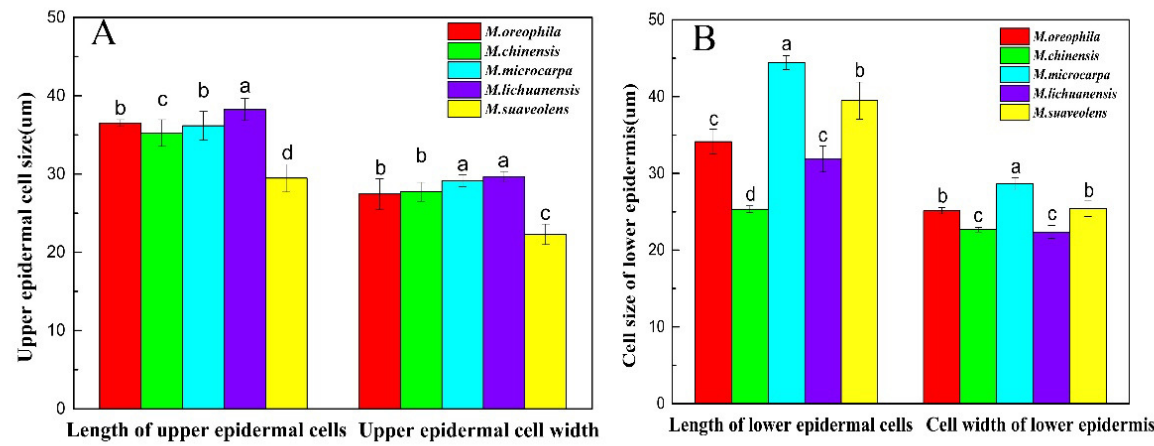

Fig. 2. Composition of epidermis cell in leaves of five Machilus species. A and B represent the length and width of upper epidermal cells and lower epidermal cells, respectively. Each value represents the mean of three replicates of each plant, and the different normal letters in the same columns indicate significant differences at $\mathrm{P}<0.05$
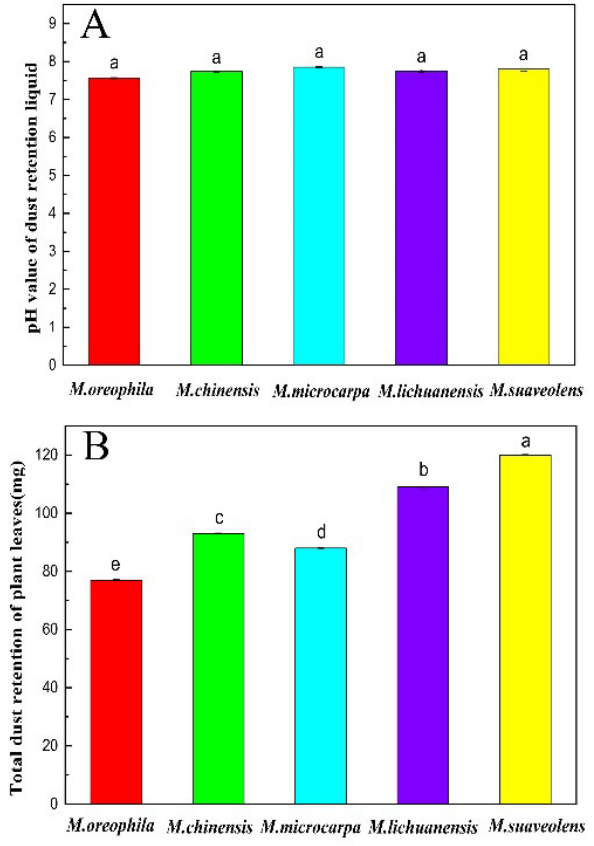

Fig. 3. Comparison of total dedusting amount and $\mathrm{pH}$ value of dedusting liquid in leaves of five Machilus species. A and B represent the $\mathrm{pH}$ value of dedusting liquid and total dust retention, respectively. Each value represents the mean of three replicates of each plant, and the different normal letters in the same columns indicate significant differences at $\mathrm{P}<0.05$

\section{Discussion}

Different plants have different dust retention capacities and the same tree species have different leaf structure and different dust retention capacity due to differences in varieties (Tallis et al., 2011; Liu et al., 2013). The leaves of plants are the main carriers of dust in the air, and each plant leaf epidermis has its own unique characteristics and plant leaves have obvious barrier, filtration and adsorption effects on particulate dust in the atmosphere, which reduces the dust content in the atmosphere (Brack, 2002; Prusty et al., 2005; Qiu et al., 2009). However, there are significant

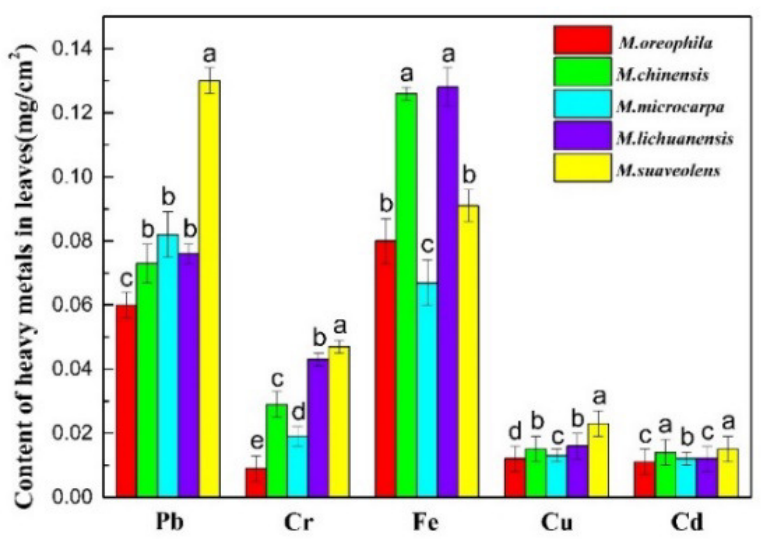

Fig. 4. Comparison of heavy metal contents in leaves of five Machilus species. Each value represents the mean of three replicates of each plant, and the different normal letters in the same columns indicate significant differences at $\mathrm{P}<0.05$.

differences in the dust-retaining ability of garden plants. A large number of studies have shown that the leaf surface roughness of plants, will affect its sedimentation effect on dust in the atmosphere (Liu et al., 2012). The leaf surface has gully structure, and the dense fluffy plants have strong dust-retaining ability. The plants with smooth and lint-free leaves have weaker dust-retaining ability, and some plant leaves are exposed to fluff or secrete oil and juice to absorb dust in the air (Sternberg et al., 2010; Fujiwara et al., 2011).

Powe, Willis (2004) and Beckett et al. (1998) studied that the relationship between leaf epidermis morphology and dust retention of some garden tree species. And they discussed the relationship between leaf structure and dust retention capacity of plants. It was found that the leaf structure with neat cell arrangement and smooth leaf surface had weak dust retention capacity, rough leaf surface, and obvious wrinkles or covered with dense epidermal hair, and the leaf with dense structure had strong dust retention capacity. The results of this study showed that the dustretaining ability of $M$. suaveolens and $M$. lichuanensis was relatively strong. When observing the leaf morphology of five plants, it was found that the epidermis of $M$. suaveolens and $M$. lichuanensis was dense, while the dust-retaining 
1228

ability was higher. The weak of $M$. microcarpa and $M$. chinensis have no epidermis, and the leaves are smooth, which is not conducive to the retention of dust. This is consistent with the previous research conclusions, but the dust retention ability of $M$. oreophila with the same leaf epidermis is not high. In other plants, it may be due to other external factors, but it cannot be denied the ability to retain dust, because plant leaf surface morphology is one of the important factors affecting plant dust retention, but it is not the only factor, there are many factors affecting plant dust retention capacity.

The amount of dust retention can intuitively reflect the strength of the dust-retaining ability (Kretinin and Selyanina, 2006).

Some scholars (Paulbeckett et al., 2006; Schaubroeck $e t$ al., 2014) have shown that the dust retention capacity of plants can be directly reflected, and the dust retention capacity of plants is positively correlated with its dust retention capacity. Schabel (1980) considered that there were great differences in dust retention ability among different plant individuals, whether broad-leaved or coniferous trees, shrubs or herbs. In this study, the total dust retention of the leaves of five Machilus species was: $M$. suaveolens $>$ M. lichuanensis $>M$. chinensis $>M$. microcarpa $>$ M. oreophila, this indicates that the dust retention capacity of plants can be directly affected by the dust retention capacity, which is consistent with previous conclusions, and further verifies that different plants have different dust retention capacity.

The content of heavy metals in plant leaves is closely related to the content of heavy metals in air pollution (Sloof, 1995; Wlau and Luk, 2001; Yin et al., 2013; Gajbhiye et al., 2016).

Fernandez and Oliva (2006), Norouzi et al. (2015) showed that the contents of heavy metals in plant leaves were significantly correlated with the concentrations of heavy metals in the atmosphere. Lehndorff and Schwark (2010) suggested that heavy elements in pine needles growing in Cologne City preferentially reflected atmospheric pollutant loads. Similarly, Simon et al. (2011) showed that the effects of air pollution in urban areas could be assessed based on elemental concentrations in foliage dust and leaf tissues of Acer pseudoplatanus. Our results are similar to theirs. The results show that different plants have different absorption and resistance to different heavy metal elements, and the same plants have different absorption capacities for different heavy metal elements, which may be due to different leaf surface morphology, which causes different reactions to different heavy metal elements. The quantitative analysis of heavy metal elements in the leaf area per unit area was found to be the strongest indicator of the retention of heavy metal elements in the leaves of $M$. suaveolens and M. lichuanensis, followed by M. chinensis and M. microcarpa, M. oreophila was the weakest. This result is consistent with the results of comprehensive evaluation of dust retention ability of leaves of five Machilus species. The higher the content of heavy metals in dust retention liquid, the stronger the dust retention ability.

\section{Conclusions}

This study has carried out related research on the dustretaining ability of five Machilus species. The results showed that there were significant differences in the leaf size and appearance of the five plants. These differences affect the dust-retaining ability more or less. From the characteristics of leaf epidermis, the epidermal cells of the Machilus were mainly irregular and polygonal. From the point of dust retention and heavy metal elements, the adsorption capacity of each plant in the Machilus was different. The dustretaining ability of five Machilus species was comprehensively evaluated. The order was: $M$. suaveolens $>$ M. lichuanensis > M. chinensis > M. microcarpa $>M$. oreophila. Therefore, when selecting a dust-reducing tree species, it is possible to select the most suitable tree species according to the characteristics of the tree species, and to maximize the dust-retaining ability of the tree species.

\section{Acknowledgements}

This work was supported by the Science and Technology Research Project of Education Department in Hubei Province of P.R.China(Q20181314)the Natural Science Foundation Project in Hubei Province of P.R.China (2017CFB390).

\section{Conflict of Interest}

The authors declare that there are no conflicts of interest related to this article.

\section{References}

Abdel-Halim SH (2003). Comparison of matrix modifiers in the determination of cadmium and lead in industrial waste water plants around Cairo by graphite furnace atomic absorption spectrophotometry. Bulletin of Environmental Contamination and Toxicology 71(6):1213-1221.

Beckett KP, Freer-Smith PH, Taylor G (1998). Urban woodlands: their role in reducing the effects of particulate pollution. Environmental Pollution 99(3):3436.

Bogo H, Otero M, Castro P, Ozafrán MJ, Kreiner A, Calvo EJ, Negri RM (2003). Study of atmospheric particulate matter in Buenos Aires city. Atmospheric Environment 37(8):1135-1147.

Brack CL (2002). Pollution mitigation and carbon sequestration by an urban forest. Environmental Pollution 117(1):195-200.

Dongarrà G, Sabatino G, Triscari M, Varrica D (2003). The effects of anthropogenic particulate emissions on roadway dust and Nerium oleander leaves in Messina (Sicily, Italy). Journal of Environmental Monitoring 5(5):766-773.

Fujiwara FG, Gómez DR, Dawidowski L, Perelman P, Faggi A (2011). Metals associated with airborne particulate matter in road dust and tree bark collected in a megacity. Ecological Indicators 11(2):240-247. 
Fernández AJ, Oliva SR (2006). The composition and relationships between trace element levels in inhalable atmospheric particles (PM10) and in leaves of Nerium oleander L. and Lantana camara L. Chemosphere 62(10):1665-1672.

Guo X, Li H, Chen H (2017). The Effects of biochar and intercropping on the $\mathrm{Cd}, \mathrm{Cr}$ and $\mathrm{Zn}$ speciation in soils and plant uptake by Machilus pauhoi.Bulletin of Environmental Contamination and Toxicology 98(4):574-581.

Gajbhiye T, Pandey SK, Kim KH, Szulejko JE, Prasad S(2016). Airborne foliar transfer of PM bound heavy metals in Cassia siamea: a less common route of heavy metal accumulation. Science of the Total Environment 573:123-130.

Kretinin VM, Selyanina ZM (2006). Dust retention by tree and shrubleaves and its accumulation in light chestnut soils under forest shelterbelts. Eurasian Soil Science 39(3):334-338.

Paulbeckett K, Freer-Smith PH, Taylor G (2000). The capture of particulate pollution by trees at five contrasting urban sites. Arboricultural Journal 24(2-3):209-230.

Liu L, Guan DS, Peart MR, Wang G, Zhang H, Li ZW (2013). The dust retention capacities of urban vegetation-a case study of Guangzhou, South China. Environmental Science and Pollution Research International 20(9):6601-6610.

Liu L, Guan DS, Peart MR (2012). The morphological structure of leaves and the dust-retaining capability of afforested plants in urban Guangzhou, South China. Environmental Science and Pollution Research 19(8):3440-3449.

LehndorffE, Schwark L (2010). Biomonitoring of air quality in the Cologne Conurbation using pine needles as a passive sampler-Part III: Major and trace elements. Atmospheric Environment 44(24):2822-2829.

Norouzia S, Khademi H, Cano AF, Acosta JA (2015). Using plane tree leaves for biomonitoring of dust borne heavy metals: A case study from Isfahan, Central Iran. Ecological Indicators 57:6473.

Prusty BAK, Mishra PC, Azeez PA (2005). Dust accumulation and leaf pigment content in vegetation near the national highway at Sambalpur, Orissa, India. Ecotoxicology and Environmental Safety 60(2):228-235.

Powe NA, Willis KG (2004). Mortality and morbidity benefits of air pollution ( $\mathrm{SO}_{2}$ and $\left.\mathrm{PM} 10\right)$ absorption attributable to woodland in Britain.Journal of Environmental Management 70(2):119-128.

Qiu Y, Guan DS, Song WW, Huang KY (2009). Capture of heavy metals and sulfur by foliar dust in urban Huizhou, Guangdong Province, China. Chemosphere 75(4):447-452.
Spitsyna NT, Skripal'shchikova LN (1991). Phytomass and dust accumulation of birch forests near open-pit mines. Soviet Journal of Ecology 22(6):354359.

Sternberg T, Viles H, Cathersides A, Edwards M (2010). Dust particulate absorption by ivy (Hedera helix L) on historic walls in urban environments. Science of the Total Environment 409(1):162-168.

Schaubroeck T, Deckmyn G, Neirynck J, Staelens J, Adriaenssens S, Dewulf J, Muys B, Verheyen K (2014). Multilayered modeling of particulate matter removal by a growing forest over time, from plant surface deposition to wash off via rainfall. Environmental Science and Technology 48(18):10785-10794.

Schabel HG (1980). Urban forestry in the Federal Republic of Germany. Journal of Arboriculture 6(11):281-286.

Sloof JE (1995). Lichens as quantitative biomonitors for atmospheric traceelement deposition, using transplants. Atmospheric Environment 29(1):11-20.

Simon E, BraunM, Vidic A, Bogyó D, Fábián I, Tóthmérész B (2011). Air pollution assessment based on elemental concentration of leaves tissue and foliage dust along an urbanization gradient in Vienna. Environmental Pollution 159(5):1229-1233.

Tomašević M, Vukmirović Z, Rajšić S, Tasić M, Stevanović B (2005). Characterization of trace metal particles deposited on some deciduous tree leaves in an urban area. Chemosphere 61(6):753-760.

Tallis M, Taylor G, Sinnett D, Freer-Smith P (2011). Estimating the removal of atmospheric particulate pollution by the urban tree canopy of London, under current and future environments. Landscape and Urban Planning 103(2):129-138.

Wu ZY, Raven PH (1994). Flora of China. Volume 17: Verbenaceae through Solanaceae. Kew Bulletin 50(4):838.

Wlau O, Luk SF (2001). Leaves of Baubinia blakeana as indicators of atmospheric pollution in Hong Kong. Atmospheric Environment 35(18):3113-3120.

Yin RJ, Wang DQ, Deng HG, Shi RH, Chen ZL (2013). Heavy metal contamination and assessment of roadside and foliar dust along the outer-ring highway of Shanghai, China. Journal of Environment Quality42(6):1724-1732. 